\title{
THE ROLE OF RELATIONAL COORDINATION IN THE RELATIONSHIP BETWEEN HIGH PERFORMANCE WORK SYSTEMS (HPWS) AND ORGANIZATIONAL PERFORMANCE
}

\begin{abstract}
This paper looks at the role relational coordination might play in understanding the relationship between high performance work systems (HPWS) and organizational performance. Research was conducted in a large financial services provider in Pakistan. Across 120 branches of the bank, data on relational coordination and on the practices making up HPWS was obtained from employees by means of a questionnaire survey. Data on branch-level performance was obtained independently of this, from the bank itself. Analysis shows relational coordination to be a mediating variable between HPWS and branch performance. Relational coordination is also a mediating variable for each of the three component parts of HPWS: ability-enhancing, motivation-enhancing and opportunity-enhancing HR practices. These results have important implications from two points of view. From the point of view of relational coordination, they show how the concept might apply in a previously under-researched sector, and also how relational coordination might act as a mediator for HR practices other than those aimed directly at enhancing employee opportunities. Breaking down HPWS into its component parts suggests that individual employee ability and motivation might also play a role. From the point of view of the HPWS-performance literature, relational coordination is revealed as a mediating variable. This suggests that the AMO (ability-motivation-opportunity) model needs to place greater emphasis on opportunity, and also that more account needs to be taken of the structural aspect of work - in particular, the degree of interdependence.
\end{abstract}

Keywords: relational coordination, HPWS, performance, AMO model, interdependence, financial sector, Pakistan 


\section{Introduction}

This paper brings together - and makes contributions to - two important areas of HR research. The first area is social relations at work and, in particular, the increasingly influential idea of 'relational coordination'. Developed in the work of Gittell and others, relational coordination is defined as 'a mutually reinforcing process of interaction between communication and relationships carried out for the purpose of task integration' (Gittell, 2002a, p.301). Relational coordination has shown itself to be a powerful way of capturing the essence of social relationships in work situations, especially when work is characterized by high levels of interdependence. At the same time, it has been shown both that particular HR practices can serve as antecedents to relational coordination (eg Gittell, 2000) and that relational coordination can act as a predictor of organization-level performance outcomes (see eg Gittell, 2001).

These links immediately bring relational coordination into contact with the second important area of HR research: the relationship between high-performance work systems (HPWS) and organizational performance (for recent overviews, see Paauwe, 2009; Guest, 2011; Jiang, Lepak, Hu \& Baer, 2012; Paauwe, Wright \& Guest, 2013). Indeed, it could be argued that this is the issue that has, in the last twenty years or so, come to dominate the HR research agenda. As is widely recognised, the existence of an association between practice and performance proved quite straightforward to establish; the real issue, almost from the outset, was how to understand the precise form this association takes. Investigation has thus come to focus on the 'black box' of organizations (Boxall, Ang \& Bartram, 2011; Boxall, Guthrie \& Paauwe, 2016; Chowhan, 2016; Jiang, Takeuchi \& Lepak, 2013, Purcell, Kinnie, Hutchinson, Rayton \& Swart, 2003). In other words, while it can be observed both what goes into the box and what comes out of it, what needs to be explored is the process by which we get from one to the other.

Up to now, research on relational coordination has made only an implicit or indirect contribution to the understanding of this process. Our aim in the present paper is to develop this into a more explicit and direct contribution to these critical HR issues. Gittell, Weinberg, Pfefferle \& Bishop (2008b, p.166; see also Gittell, 2006) have suggested that relational coordination could contribute to 'an emerging relational perspective on high-performance work systems ... in contrast to a focus on individual human capital ... or on motivation and commitment ...', and the present paper aims.to show the form this contribution might take. 
More specifically, we address the question of the role that relational coordination might play as a mediating variable in the relationship between HPWS and organizational performance. This question is examined in the setting of a single large bank, providing financial services in Pakistan. This setting is characterized by a high degree of interdependence in the organization of work, and is thus one in which we might expect relational coordination to be significant. It is also operating in a sector in which HPWS have shown to be important, in terms both of managerial intent and of employee experience. The size and structure of bank mean that meaningful performance data could be gathered at the workplace or branch level, and this was analysed in conjunction with data on HPWS and relational coordination collected by a survey of individual employees.

The findings of the research represent important contributions to the two areas that we bring together in this paper. From the point of view of relational coordination, they show how this concept might apply in a previously under-researched sector, and also how it might act as a mediator not just for HR practices that are aimed directly at encouraging it, but also for generic HPWS or HR practices as a whole. Moreover, breaking down HPWS into their component parts suggests that individual employee ability and motivation might play a role in promoting relational coordination and, in turn, workplace performance. Looking at things from the point of view of the HPWS-performance literature, relational coordination is thus revealed as a mediating variable. This suggests that the AMO (ability-motivation-opportunity) model needs to place greater emphasis on opportunity, and also that more account needs to be taken of the structural aspect of work - in particular, the degree of interdependence.

The paper is structured as follows. Following this introduction, the conceptual background to the analysis is presented. This involves consideration of the idea of relational coordination and an examination of the most salient aspects of the HPWS-performance debate. The third main part of the paper deals with the design of our research and the methods we employed, and the findings of the research are presented in the fourth section. The fifth and final section of the paper provides a discussion of these findings, highlighting the contributions they make to an understanding of the conceptual issues raised in the literature review. 


\section{Conceptual background}

\section{Relational coordination}

In the words of Gittell (2002a, p.301), 'relational coordination is a mutually reinforcing process of interaction between communication and relationships carried out for the purpose of task integration'. From an organization's point of view, the basic issue is how it coordinates its various functions or departments. This thus depends on two things: first, communication —its frequency, timeliness, accuracy and problem-solving orientation; and second, relationships, which in turn are based on shared knowledge, shared goals and mutual respect (see eg Gittell, 2002a, p.301). While these individual elements might be familiar ones, what is distinctive about relational coordination is the way in which these elements are brought together into a coherent package capable of aiding our understanding of the nature and effects of the coordination of work.

Using relational coordination also allows closer links to be made between the social aspects of coordination and the more technical or structural aspects of the organization of work. This is because the relationships found in relational coordination are those between work roles rather than between individual employees (see Gittell, Seidner \& Wimbush, 2010). The need for effective relational coordination will thus be greater in settings where there is a high degree of interdependence in work processes, especially when these processes are uncertain and timeconstrained (Gittell, 2000). These conditions can often be found in service sector settings, and evidence to support the idea of relational coordination has been found in such areas as flight departures and health and social care.

In the case of flight departures, Gittell (2001; see also Gittell, 2000) showed how relational coordination was essential to the organization of this key component of airline performance. Getting flights away on time involved as many as 12 different functions, these including the mechanics and re-fuellers needed to ensure the plane is in a physical state to fly; the gate agents and ticketing agents needed to ensure the passengers are on board and ready to go; the cabin cleaners and caterers needed for the comfort of passengers; and the pilots and flight attendants needed to get the plane off the ground. A number of airlines were examined, and, within each of them, the relationships between each one of the functions and each of the other functions were assessed on the basis of relational coordination. A positive link was found between the degree of relational coordination and flight departure performance, with the latter 
looked at in terms of both quality and cost. A particular concern in this case (Gittell, 2001) was the role played by supervisory spans of control. Contrary to any expectations engendered by 'post bureaucratic' organization theories, a narrow span was found to be more effective than a wide one - a finding Gittell (2001) attributed to the closeness of the supervisory relationship that the narrow span allowed.

The ideas of relational coordination have also provided insights from studies carried out in the healthcare sector (Gittell, 2002b, 2008; Gittell, Fairfield ... \& Zuckerman, 2000; Gittell, Weinberg, Bennet \& Miller, 2008a; Noel, Lanham, Palmer, Leykhum \& Parchman, 2013). Gittell (2002b) looked at the relations between the different functions needed to care for patients undergoing joint replacement surgery in acute hospitals: 'physicians, nurses, physical therapists, case managers, and social workers' (Gittell, 2002b, p.1412). Gittell et al. (2000) again demonstrated a positive relationship between relational coordination and the quality of care, but relational coordination was also looked at as the means through which other coordination mechanisms might have their effect (Gittell, 2002b). As expected, it was found to act in this way for the mechanisms of boundary spanning and team meetings, but also, more unexpectedly, for organizational routines a well. These routines, it was argued, were effective through complementing, rather than substituting for, the interactions captured by the idea of relational coordination. In addition, Gittell (2008) demonstrated how relational coordination could provide for the coping mechanisms that would allow organizations in the healthcare sector to be more resilient in response to the severe external pressures they faced.

We can thus see the strength and versatility of relational coordination as a means of understanding inter-functional relations, especially in settings where there is a high degree of interdependence in the work process. What is also clear is that relational coordination is positioned as an intermediary variable - as something having both antecedents and outcomesand it is looking at it explicitly in this way that allows us to bring it together most fruitfully with the broader debates surrounding the links between HPWS and organizational performance. Turning first to antecedents, we can see, for example, how Gittell et al. (2008a) identified how, in a particular healthcare setting, relational coordination could act as a mediator between job design and certain measures of efficiency and quality. While this was fairly narrow in its focus, other research on relational coordination has examined how it might arise from broader systems of work organization. Gittell's (2000) study of flight departures identified a range of work 
mechanisms and practices, which included the use of cross-functional liaison roles and the use of team working as a key selection criterion. A similar conclusion was reached on the basis of the research in healthcare, where, as we have seen, Gittell (2002b) showed how relational coordination could be seen as the means through which certain coordinating mechanisms were of impact at the level of the organization as a whole.

The outcomes of relational coordination have been expressed in terms of a variety of organizational performance measures. These can, in broad terms, be seen to arise from the better communication ties that relational coordination engenders between employees in different functional areas (Noel et al., 2013). Because relational coordination is established as a result of relationships based on shared goals, shared knowledge and mutual respect, and because it is backed by frequent, timely, accurate, and problem-solving flow of quality communication, it is argued that this gives employees the opportunity to employ organizational resources in a more effective manner (Gittell et al., 2010). Gittell et al.'s (2008b) study of nursing homes, although able to identify a link between relational coordination and job satisfaction, was in fact unable to establish this as the route through which relational coordination was of impact on broader quality outcomes. On the other hand, as we have already seen, the work in the healthcare sector established an association between relational coordination and a number of care-based outcomes (Gittell et al., 2000); while relational coordination in the organization of airlines' flight departures was found to be associated positively with quality and efficiency (Gittell, 2001).

As things stand, therefore, consideration of relational coordination in the context of the broader practice-performance debates has been restricted to looking at those HR practices with which relational coordination might be thought to have the most direct relationship. This is most strongly evident in Gittell et al.'s (2010) study of patient care. Picking up on the earlier study (Gittell, 2000), a number of work practices were identified that focused on developing relationships between employees — a specifically cross-functional approach to selection, conflict resolution, accountability in performance management, rewards, meetings and boundary spanning. The association between these practices and quality and efficiency outcomes was found to be mediated by relational coordination. These findings, argued Gittell et al. (2010), not only showed how formal practices could encourage the relationships that improve organizational performance, but 'articulate[d] a novel relational pathway through which highperformance work practices contribute to performance' (Gittell et al., 2010, p.503). 
In the present paper we extend this to look at the part relational coordination might play in the relationship between organizational outcomes and HR systems or high performance work systems (HPWS) as a whole. In doing so, we are responding to the call made by Gittell et al. (2008b, p.166; see also Gittell, 2006) who argued that relation coordination could contribute to 'an emerging relational perspective on high-performance work systems ... in contrast to a focus on individual human capital ... or on motivation and commitment ...'. In order to do this, and, in particular, to show how the present paper brings together relational coordination with the broader HPWS-performance debates, it is to developments in the latter area that we now turn.

\section{Theorizing the HPWS--performance link}

Debates on the HPWS-performance link have been raging for over twenty years (for recent overviews, see Paauwe, 2009; Guest, 2011; Jiang et al., 2012; Paauwe et al., 2013), and, over this period, it is the ability-motivation-opportunity (AMO) model that has emerged as the dominant framework for structuring our understanding of the issues involved (Appelbaum, Bailey, Berg \& Kalleberg, 2000; Boxall \& Purcell, 2016; Boxall et al., 2016; Jiang et al., 2013; Paauwe, 2009). As research has tried to make visible what goes on inside the organizational 'black box', the hypothesized routes through which HPWS might have their effect have become more numerous and complex. One important development is that there has been increasing attention paid to the relatively neglected area of the structural and social relations represented by the ' $\mathrm{O}$ ' of the AMO framework. As has recently been argued, attempts to understand these 'transmission mechanisms' have tended to focus either on the ' $\mathrm{A}$ ' - the abilities or the skills and knowledge of employees - or on the ' $\mathrm{M}$ '- the levels of motivation that employees might experience (Boxall et al., 2016). As we have seen, it is the opportunities given to employees by relational coordination that allow the employees to use organizational resources in a more effective manner (Gittell et al., 2010). This paper thus takes up the call made Boxall et al. (2016, p.104), that 'we must pay better attention to the "O" variable'.

In order to be in a position to do this, we need first to pick our way through a number of the issues facing any research in this area. The first of these is what practices to include under the heading of HPWS. Heavey et al.'s (2013, esp. pp.144-147) review of existing work is useful in this respect, revealing a rather odd mixture of dissensus and consensus. On the one hand, they identify 36 different categories of practice, and no one category is included in all of the studies 
under review. On the other hand, they identify a break between the six most-used categories and the rest. The six are: compensation, training, selection, performance appraisal, communication and the HR function. This consensus view is reflected in the present paper. More detail on the choices made, and the precise statements used to capture the different practices, are presented in the methods section, below (see also Appendix A). In fact, seven categories of practice are used: job or employment security, training, employee participation, job description, information sharing, contingent compensation and performance appraisal. Four of the six most-used categories identified by Heavey et al. are thus included: compensation, training, appraisal and, in the form of information sharing, communication. Of the three other categories of practice used (participation, job description and employment or job security), two-participation and job security - were ranked seventh and eighth respectively in Heavey et al.'s review.

A second issue is how the effects of different elements of HPWS might be differentiated from each other. In terms of the AMO model, the distinction is, of course, between abilityenhancing, motivation-enhancing and opportunity-enhancing HR policies or practices (see Jiang et al., 2012), and we make use of this distinction in the present paper. Categorizing each of the individual HR practices is also relatively straightforward, since, as Jiang et al.'s (2012) metaanalysis shows, there is a fair degree of consensus on this issue. In looking at the practices used here, it can be seen quite clearly that training can be regarded as ability-enhancing; job security, contingent compensation and appraisal as motivation-enhancing; and job description, employee participation and information-sharing as opportunity-enhancing practices.

A third issue is how the idea of 'organizational performance' is treated. Dyer and Reeves (1995) identified a hierarchy of performance outcomes, and this is echoed in Guest's (1997) distinction between 'proximal' and 'distal' indicators of performance effects. Thus while distal indicators, such as the overall financial performance of an organization, might be the ultimate concern, it is through more proximal indicators, such as productivity and quality, that any effects will be achieved (see Peccei, Van de Voorde \& Van Veldhoven, 2013, pp.18-19) These distinctions, however, also need to be considered in terms of organizational hierarchies. Large organizations are likely to be made up of a number of different workplaces or operational units, and it is at this level that the direct or proximal performance effects of HPWS will be felt. A focus on the workplace is made all the more necessary by the increasing emphasis being placed on social relations in production or service delivery — a matter that we examine explicitly below. 
As we have seen, it is primarily in terms of more operational outcomes that the impact of relational coordination has been assessed. Not only are such relations more likely to be present and observable at the workplace level, but, by their nature, it might be expected that they will not be the same across the organization as a whole. In looking at social relations, and trying to say something about their antecedents and outcomes, it is precisely such variation between workplaces that is required. It is at this level - the workplace or the branch — that the idea of organizational performance is employed in the present paper.

Having established the position of the present paper on these three key issues, we return to Boxall et al.'s call (2016, p.104), that 'we must pay better attention to the "O” variable', and, in particular, to the role that social relations - in our case as represented by relational coordination - might play in this. In terms of relationships amongst employees, the idea of 'social capital' has been examined as a possible route through which HR policies might have their effect. Leana and van Buren (1999) show how this concept - 'an asset that inheres in social relations and networks' (1999, p.538)—can be applied at an organizational level. In particular, they attempt to identify two things: the different routes through which employment or HR practices might encourage the development of social capital, and the different routes through which social capital might have organizational-level benefits. These links have been investigated empirically by Gant, Ichniowski and Shaw (2002) in their study of social capital amongst workers on steel-finishing lines. Gant et al. show how those lines in which HRM is 'involvement-oriented' rather than 'control-oriented' are also those on which the workers have the higher levels of social capital needed for more successful problem-solving activity.

Other work on social relations has been located more explicitly as part of HPWSperformance debates. Evans and Davis (2005) have put forward an organization's internal social structure as a mediating variable in the relationship between HPWS and organizational performance outcomes. In the same way, Collins and Smith (2006) show how 'commitmentbased' HR policies in high-technology companies contributed positively to a social climate based on trust and co-operation. This was shown to give rise to better knowledge exchange and combination on the part of knowledge workers and, in turn, to higher levels of organizational performance. Collins and Clark (2003) also showed how certain HR practices might contribute to the development of social networks of senior managers in such companies. Again, this appeared to improve decision-making and, in turn, some measure of financial performance. 
The research that — explicitly or implicitly_highlights how relationships between employees might give greater prominence to the 'O' of AMO, however, has paid little attention to the more structural aspects of work organization. Relational coordination, as we have seen, is likely to be of greater importance when work organization is interdependent in nature, and, if the significance of relational coordination can be established, this suggests one way in which the AMO model as a whole might be developed. Wright and Nishii (2013) are among the few who at least allude to work structures, drawing on Thompson's (1967) classic distinction between the pooled, sequential and reciprocal forms of interdependence. Under low or pooled interdependence, argue Wright and Nishii, improved individual performance translates quite easily into unit-level performance, since it is merely a question of aggregating the individual improvements. When interdependence is high, on the other hand (ie when it is reciprocal), 'increasing individual performance does not necessarily translate into increased unit performance' (Wright \& Nishii, 2013, p.109). Even here, this argument is not developed at any length, and little or no evidence is provided in its support.

However the ' $\mathrm{O}$ ' is operationalized, it is clear that it remains the least developed part of the AMO framework. There are those such as Boxall (2013), who do recognize the contributions of Evans and Davis (2005) and others, and who see this as an area on which increasing focus is being placed. From another influential account of the model, however, the impression can be gained that there are significant obstacles which still need to be overcome. This is Jiang et al.'s (2012) meta-analysis, which provides us with a rather lop-sided version of the AMO model — one in which 'opportunity' does not seem to be treated in the same way as 'ability' or 'motivation'. While, as we might expect, ability-enhancing policies are able to act on employee ability, and motivation-enhancing polices likewise on employee motivation, opportunity-enhancing HR practices appear to have no direct target of their own (see Jiang et al., 2012, eg p. 1274, Figure 1). Instead, opportunity-enhancing practices are hypothesized only to work indirectly, through either or both of employee ability (or human capital) and employee motivation. Jiang et al. (2012) do little to explain all this: 'In line with the literature,' they say, 'we focus on the mediating roles of human capital and employee motivation' (2012, p. 1267). Indeed, Jiang et al. (2012) go so far as to try and distance social relations from the AMO model. Their focus on the mediating role of employees, they claim, 'does not exclude other paths through which HRM can help increase financial outcomes' (Jiang et al., 2012, p. 1270). These 'other' paths include 
explicit reference to the relational coordination of Gittell et al. (2010), but the intention seems to be separate them from, rather than integrate them with, the AMO model as a whole. On the other hand, if the significance of relational coordination in this area can be more firmly established, then this might have wider implications for the way in which the model is conceptualized.

While our focus on relational coordination means that we do need to pay close attention to the 'O' of AMO, we also need to recognise the model's essentially multidimensional nature. Obeidat, Mitchell and Bray (2016) provide evidence of the utility of the AMO model, by looking separately at the performance effects of the sets of policies relating, respectively, to ability, motivation and opportunity. But, more than this, as Boxall and Purcell (2016, p. 160) argue, 'we need to consider all three AMO variables and how they interact'. Thus in the model proposed by Jiang et al.'s (2012) meta-analysis, for example, motivation-enhancing policies are expected to have their ultimate effect on performance not just through motivation itself, but also, but more indirectly, by being able to attract employees with higher levels of ability. Likewise, for Boxall and Purcell (2016), opportunity-enhancing polices, such as the design of work, could both provide intrinsic motivation for employees and encourage them to enhance their ability (see also Sterling \& Boxall, 2013).

\section{Research hypotheses}

We can now draw together the various strands of our review of the secondary literature, and set out the formal hypotheses that will be tested through an analysis of our primary data (see also Figure 1). Our concern is to see whether relational coordination can, in Gittell et al.'s (2008b, p.166) words, contribute to 'an emerging relational perspective on high-performance work systems' which does not restrict itself to a focus on individual employee ability and motivation. We thus start with the potentially mediating role that relational coordination might play in the overall relationship between HPWS and organization-level performance:

Hypothesis 1: Relational coordination partially mediates the workplace-level relationship between HPWS, as whole systems, and performance outcomes. 
Looked at in terms of the AMO framework, moreover, we need to see whether any such relationship can be part of the 'better attention' that Boxall et al. (2016, p.104) recommended be paid to the ' $\mathrm{O}$ ' of opportunity. Our second hypothesis thus focuses on those HR practices that are opportunity-enhancing in nature:

Hypothesis 2: Relational coordination partially mediates the workplace-level relationship between opportunity-enhancing HR practices and performance outcomes.

At the same time, the interconnected nature of the AMO model means that we would not expect the opportunity-enhancing practices to be the only ones having their effects through relational coordination. In line with the analysis discussed at the end of the previous section, it is suggested that the more able and the better motivated employees would be the ones more likely to take advantage of whatever opportunities are offered to them. While we do not have data on ability and motivation themselves, we do have it at one remove, on ability-enhancing and motivation-enhancing practices respectively. We therefore test the following two-part hypothesis:

Hypothesis 3: Relational coordination partially mediates the following workplace-level relationships: (a) between skill-enhancing HR practices and performance outcomes, and (b) between motivation-enhancing HR practices and performance outcomes.

\section{Figure 1 about here}

\section{Methods}

\section{Research setting and data collection}

Research setting

The hypotheses are tested on data collected in a single company in the financial sector of Pakistan. The bank in the study is one of the largest and most banks in the country, having a nationwide branch network of more than 1300 branches and an agency relationship with more 
than 3000 banks worldwide. It operates in all major cities and business centres across the main regions and provinces of Pakistan (State Bank of Pakistan, 2012). The branches of the bank are similar to each other in terms of size, technology, and organizational structure, and each branch offers the same range of services to their client base.

\section{Data collection: sampling and procedure}

Data was collected in two main ways. Data on relational coordination and the HR practices making up HPWS was collected through a questionnaire survey of employees within bank branches, while data on workplace or branch-level performance was obtained independently from the bank itself. The source of data has been an issue in research into relational coordination, where researchers have recognised that the best source is employees themselves. Gittell et al. (2010, p. 503) acknowledged that a limitation of their own work was 'the use of [administrator] interviews rather than survey instruments to measure work practices,' a limitation to which we are not subject in the present study.

The physical collection of the data was done in collaboration with the Institute of Bankers Pakistan, a leading provider of technical training services for the banking sector. The Institute provided administrative support and research facilities throughout the process. Prior approvals were solicited from the bank's head office and those regional offices involved in the study. The survey was conducted with the help of the bank's central and regional HR departments. A sample of 340 branches was selected through a two-step stratified proportionate random sampling process, and these were surveyed in the period August to October 2011. Keeping in view the distinct geographical distribution of the bank's operations, it was not feasible to reach

all employees in these branches. Therefore, it was decided to include bank branches from three areas: Central Punjab, Federal Areas Islamabad, and Khyber Pakhtunkhwa (KPK). The list of branches was taken from the head office of the bank. The total number of bank branches in these areas surveyed constitutes 57 percent ( 755 branches) of the total branch network. From the total number of 755 branches in areas of Central Punjab, Federal Areas Islamabad, and KPK, a random sample of $45 \%$ branches was drawn from each area to represent proportionate participation of branches from all over the country. Table 1 presents the information about the number of branches included in the study. Upon approval from head office and regional offices, branches were personally contacted and prior appointments were booked with each for 
administering the survey. Utilising a small team of research assistants, the survey was personally administered to employees in the four categories of manager and officers in operations, credit, and cash functions at each branch, each branch having at least one respondent from each of these four main functions. In total, 3500 questionnaires were distributed and, of these, 2280 were returned, of which 1563 were usable.

\section{Table 1 about here}

Data on branch-level performance in the bank was also obtained in collaboration with the Institute, who were able to assure the bank on issues of how the data was to be protected and used. The bank agreed to provide branch-level performance measures including total deposits, advances, and branch profit. Performance data was provided by 120 branches, covering a total of 887 employees. Branch performance measures were collected eight months after the survey, in July 2012. Longitudinality is an issue that has bedevilled HPWS-performance research (Gerhart, 2013; Wall \& Wood, 2005; Wright, Gardner, Moynihan \& Allen, 2005), and, in the present study, only some part of the data might be considered to be of an 'authentic' longitudinal nature (Wall and Wood, 2005). As with many other studies in this area, practical constraints on research design made a greater degree of longitudinality difficult to achieve, and this of course must be taken into account in the interpretation of the results.

\section{Measures}

\section{HPWS and HR practices}

We have already seen that the question of which practices to include as part of HPWS is one that has greatly exercised researchers in this area. As noted earlier, the seven categories of practice used here - employment or job security, training, employee participation, job description, information sharing, contingent compensation and performance appraisal-mean that the present study is broadly in line with the consensus identified in Heavey et al.'s (2013) review. Of the six most popular categories of practice identified in the review, the two not used in the present study are 'selection', which was excluded on the grounds that this was made up of practices 
carried out centrally in the bank rather than at branch level (see also Liao, Toya, Lepak \& Hong, 2009, p.378), and 'organizational structure', which, despite its name, relates to the way in which the HR function operates, and, to the extent it can be considered a 'practice' at all, is something again that is carried out centrally rather than at the level of the branch. It should also be noted that the 'information sharing' category relates to information flows of a vertical nature within the organizational hierarchy, such as team briefings. It can thus be distinguished from the horizontal communication that forms part of relational coordination.

The extent of the selected practices was measured on the basis of employee responses to statements in the survey (see Appendix A). Responses were on a 5-point Likert scale, ranging from 'strongly disagree' (1) to 'strongly agree' (5). Again, this is in line with practice adopted in the studies surveyed by Heavey et al. (2013). The practices themselves were represented as follows. Employment security, training, employee participation and job description each used measures developed by Delery and Doty (1996); information sharing and contingent compensation were based on the measures of Zacharatos et al. (2005); and performance appraisal was measured using five items from Singh (2003), Delery and Doty (1996) and Snell and Dean (1992).

To create an index of HPWS for each respondent, the subscale aggregation method was employed (Liao et al., 2009). This study follows an additive approach for aggregating high performance work practices into an index. An additive approach assumes that the influence of high performance work practices on particular objective are distinct, and using more of these high performance work practices should result in expanded levels of particular objectives. In accordance with the regular process adopted by the HPWS literature, this study aggregated various measures of individual HR practices into a unitary index that measures HPWS (Guest, 1999; Lepak et al., 2006; Macky and Boxall, 2007; Way, 2002), and this study also follows the subscale aggregation method (Zacharatos et al., 2005; Liao et al., 2009). In the first instance, subscale scores were calculated by averaging across all items of the same HR practice (eg employment security). An average across the seven individual practices was used to create an index of HPWS for each respondent. The subscale aggregation method for each practice and for the HPWS index were justified by the high value of internal consistency across scales.

As we also saw earlier, the HR practices that made up HPWS were divided up according to the basic categories of the AMO model. Ability-enhancing practices included just training; 
the motivation-enhancing practices were employment security, contingent compensation and appraisal; and the opportunity-enhancing practices, employee participation, job description and information-sharing. Using the subscale aggregation method, an average across the three individual practices was used to create an index of opportunity-enhancing HR practices for each respondent. Similarly, an index for skill-enhancing HR practice was calculated by averaging across all items of the training HR practice. In the same manner, an average across the three individual practices was used to create an index of motivation-enhancing HR practices for each respondent. These indices were also justified by their high value of internal consistency.

\section{Relational coordination}

The measure of inter-functional coordination was based on the interactions between the four main groups of employees: those dealing with operations, those dealing with cash, those working in credit, and those with management responsibility. These groups work interdependently in order to carry out the two main areas of the branch's work: accepting deposits and making advances. The bank's deposits are processed through operations and the cash function, with compliance ensured through the credit function. In the case of advances, the lending proposals are routed through the credit function, processed through operations, with eventual payments made through the cash function. Branch managers are directly involved at all levels with operations, credit and cash function. Employees in the operations, credit and cash functions accounted for 39, 23 and 17 per cent of the sample respectively, with branch managers accounting for the remaining 21 per cent.

Relational coordination was measured using an adapted version of the survey developed by Gittell (2001). Respondents were asked to answer each question in the survey with respect to each of the other functions. Survey items included the following: 'Do people in each of these departments communicate with you in a timely way about branch working?'; and 'When a problem occurs with branch working, do the people in each of these departments work with you to solve the problem?'. Responses to these items are measured on a 5-point Likert scale, and the same procedure adopted for the HPWS unitary index was followed for relational coordination. 


\section{Workplace performance}

In looking at performance, the focus was on those measures with which the branches themselves were most concerned (see Paradi, Yang \& Zhu, 2011). In recent years, researchers have adopted three approaches to examine the performance of a bank at the branch level: production, intermediation, and profitability (Paradi et al., 2011). In the production approach, bank branches are analysed as utilizing capital and labour to generate deposits and advances, while in the intermediation approach, bank branches are assessed in terms of the process through which a bank's deposits are transformed into loans. In the profitability approach, banks are assessed on the basis of how well the bank branches originate profits from their utilization of bank's assets, capital, and labor. In terms of the issues around performance discussed earlier in this paper, we can see that the production approach would give the most 'proximal' measure of performance, and the profitability approach the most 'distal' (Guest, 1997).

Two measures of branch performance are used in the present study. Taking the production approach would give us the most proximal performance indicator, and here we measure performance in terms of the level of deposits generated per head in the branch (deposits/employee). It is on this measure of performance that we would expect any (mediated) HR effect to be of greatest significance. The second measure of branch performance used is the ratio of advances to deposits (advances/deposits). This can be thought of as being based on the intermediation approach to performance, and so more distal than deposits/employee, but still more proximate than measures based on branch profitability. Identical sets of measures of branch-level performance were gathered across 120 bank branches. The bank's regional offices, and, in some cases, main branches, provided branch-level data on deposits, advances and profits. Figures on the number of staff were obtained from each branch.

\section{Control variables}

While control variables have been a feature in HPWS-performance research, this has not always been the case in research on relational coordination. In Gittell et al.'s (2010) attempt to link work systems, relational coordination and performance, an acknowledged limitation was the 'lack of employee-level control variables other than the functional identity of the respondent' (2010, p.503). The present study was able to obtain data on age, qualification, experience, gender and length of service in the branch. 


\section{Instrument validation}

Factor analysis

An exploratory factor analysis with principal components technique of factor extraction and varimax rotation method was conducted on all individual HPWS items. Prior to performing the principal components analysis on the 29 items of HPWS, the suitability of the data for exploratory factor analysis was determined. In order to get an optimal solution for cross loadings, three items were removed from the list of indicators in repeated factor analysis. The results of the analysis indicated the presence of seven factors with eigenvalues exceeding 1.0, and together these seven factors explain $61 \%$ of the total variance in HPWS. The same procedure was adopted with respect to the degree of relational coordination.

\section{Reliability analysis}

Cronbach's alpha was used to evaluate the internal consistency of skill, motivation, opportunityenhancing HR practices, overall measure of HPWS and relational coordination. The coefficient values for each scale were approximately equal to, or more than, the recommended level of 0.7. To assess interrater reliability, two measures of intra class correlation coefficient, ICC (1) and ICC (2), were computed. These are set out in Table 2, with the results providing justification for treating HPWS and the degree of relational coordination as unit-level constructs.

\section{Table 2 about here}

\section{Validity analysis}

Interrater agreement (IRA) was estimated for each dimension score using indices developed by James, Demaree \& Wolf (1984) to ascertain justification for aggregation and determine the similarity of ratings within bank branches in an absolute agreement sense. The values of IRA indices ranges from 0 to 1 with values of 0.70 having been considered the traditional-off cut

point (LeBreton, Burgess, Kaiser, Atchley \& James, 2003). LeBreton and Senter (2008) provided a more-inclusive set of indices values guidelines, suggesting IRA values from 0.00 to 0.30 be 
interpreted as lack of agreement, 0.31 to 0.50 as weak agreement, 0.51 to 0.70 as moderate agreement, 0.71 to 0.90 as strong agreement, and 0.91 to 1.00 as very strong agreement.

The average $\mathrm{r}_{\mathrm{wg}(\mathrm{j})}$ of HPWS for managers, employees in operations, credit, and cash functions were $0.93,0.91,0.92$, and 0.89 respectively (see Table 3 ). These values exceed the recommended value of 0.70 suggesting a very strong agreement for managers, operations, and credit functions, and strong agreement for the cash function. With regard to relational coordination, the average $\mathrm{r}_{\mathrm{wg}(\mathrm{j})}$ of the degree of relational coordination for managers, operations, credit, and cash functions were $0.91,0.88,0.87$, and 0.87 respectively. These values also exceed the recommended value of 0.70 suggesting a very strong agreement for managers, and strong agreement for operations, credit, and cash functions. These results provide justification for aggregating individual level scores to the branch level for the HPWS and relational coordination dimensions.

\section{Table 3 about here}

\section{Results}

\section{Descriptive statistics}

Descriptive statistics for HPWS, the component sets of practices, relational coordination and the two measures of branch performance are shown in Table 4. The mean values of branch-weighted HPWS and relational coordination were $3.53(\mathrm{SD}=0.29)$ and $3.57(\mathrm{SD}=0.32)$ respectively, representing high levels of both variables. Amongst the HR practices, the mean values of opportunity-enhancing, skills-enhancing and motivation-enhancing HR practices were 4.01, 4.20, and 3.86 respectively. Table 4 shows HPWS to be significantly positively correlated with both relational coordination among employees and operational outcomes of branch performance. The opportunity, skills and motivation-enhancing HR practices were also each significantly correlated with relational coordination and branch performance. 


\section{Table 4 about here}

\section{HPWS as whole systems, relational coordination and workplace performance}

The three-step method recommended by Baron and Kenny (1986) was adopted to assess the mediating role of relational coordination in the overall effect of HPWS on workplace-level outcomes. Table 5 presents the summary statistics for the regression analysis of HPWS with branch performance. Results reveal a significant positive association between the extent of HPWS and deposits per employee $(\beta=74.19, \mathrm{p}<0.001)$ and advances to deposits ratio $(\beta=16.38, \mathrm{p}<0.001)$. The results provides sufficient evidence for the first condition of mediation.

In order to assess mediation, the degree of relational coordination and HPWS were both added into the Model (XMY). Results showed that the coefficient of HPWS with deposits/employees and advances /deposits significantly diminished in Model (XMY). These results satisfy the three conditions of mediation convincingly. Additionally, the Sobel (1982) test was conducted, and this confirmed a mediating role for relational coordination $(\mathrm{z}=7.59$ and $3.20, \mathrm{p}<0.05$ respectively). Overall, these results support Hypothesis 1, that relational coordination partially mediates the workplace-level relationship between HPWS, as whole systems, and performance outcomes.

\section{Table 5 about here}

\section{Opportunity-enhancing HR Practices, relational coordination and workplace performance}

Results suggested that opportunity-enhancing HR practices were significantly associated with relational coordination $(\beta=0.085, \mathrm{p}<0.001)$, deposits/employee $(\beta=27.25, \mathrm{p}<0.001)$, and advances/deposits $(\beta=2.918, \mathrm{p}<0.001)$. To assess mediation, relational coordination was included in the Model (XMY) (see Table 6). A comparison between results of models revealed that the regression coefficient of opportunity-enhancing HR practices diminished significantly 
when the degree of relational coordination was added $(\beta=27.25$ to $23.365, p<0.05$; and $\beta=$ 2.918 to $1.617, \mathrm{p}<0.05)$. This suggests that relational coordination partially mediated the relationship between the opportunity-enhancing and operational outcomes. The results of the Sobel test provided further evidence of this $(\mathrm{z}=3.65$ and $2.78, \mathrm{p}<0.05$ respectively). There was thus support for Hypothesis 2, that relational coordination partially mediates the workplace-level relationship between opportunity-enhancing HR practices and performance outcomes.

Table 6 about here

\section{Skills- and Motivation-enhancing HR Practices, relational coordination and workplace performance}

Results indicated that skill-enhancing HR practices showed a significant association with relational coordination $(\beta=0.064, \mathrm{p}<0.001)$, deposits/employee $(\beta=9.272, \mathrm{p}<0.001)$, and advances/deposits $(\beta=1.828, \mathrm{p}<0.001)$. Relational coordination was added in the regression Models (XMY) (see Table 7). Results suggested that the regression coefficients of skillenhancing HR practices reduced significantly in Model XMY when the relational coordination was added $(\beta=29.272$ to 5.892, $\mathrm{p}<0.05$; and $\beta=1.828$ to $0.827, \mathrm{p}<0.05$ ). Additional analysis of the Sobel test also added support to this $(\mathrm{z}=1.785$ and $2.635, \mathrm{p}<0.05$ respectively). There was thus support for Hypothesis 3(a), that relational coordination partially mediates the workplace-level relationships between skill-enhancing HR practices and performance outcomes.

\section{Table 7 about here}

Finally, results also showed a positive association between motivation-enhancing HR practices, relational coordination $(\beta=0.088, \mathrm{p}<0.001)$, deposits/employee $(\beta=3.212, \mathrm{p}<0.001)$, and advances/deposits $(\beta=5.114, \mathrm{p}<0.001)$. To test for mediation, relational coordination was added into the model (see Table 8). Comparing the results of regression models, the coefficients 
of motivation-enhancing HR practices diminished significantly with the addition of relational coordination $(\beta=3.212$ to $1.782, \mathrm{p}<0.05$; and $\beta=5.114$ to $3.865, \mathrm{p}<0.05)$. This was confirmed by the results of the Sobel test $(\mathrm{z}=1.98$ and $2.356, \mathrm{p}<0.05$ respectively). Support was thus found for our final hypothesis, Hypothesis 3(b), that relational coordination partially mediates the workplace-level relationship between motivation-enhancing HR practices and performance outcomes.

\section{Table 8 about here}

\section{Conclusions and contributions}

Overall, therefore, our results provide support for Hypotheses 1, 2, 3(a) and 3(b) - taken together, this means that relational coordination mediates the workplace practiceperformance relationship, not only with regard to HPWS as whole systems, but also in regard to each of the three constituent parts of HPWS: opportunity-enhancing, skillenhancing, and motivation-enhancing HR practices respectively.

But what are the wider implications of these results for our two main areas of concernrelational coordination and the HPWS-performance debate? In terms of the former, we can identify three important contributions to ongoing developments. We observed in our literature review how studies of relational coordination have so far been confined to a limited range of settings, especially healthcare (eg Gittell, 2008; Gittell et al., 2008a) and flight departures (eg Gittell, 2000; 2001). The first contribution of the present study is to show that relational coordination is capable of generating insight in financial services, another sector in which work systems can be characterized as being interdependent in nature. In contrast to Gittell et al.'s (2010) study of patient care, moreover, this study was able both to capture work practices on the basis of employees' own responses and to control for a number of potentially important employee characteristics.

Second, while confirming that relational coordination has a link to workplace or operational outcomes, we have been able to show how consideration of the antecedents of relational coordination can be expanded to cover what might be seen as generic HPWS. Again, 
previous work has been rather restricted in the kind of work systems it looked at. Gittell et al. (2010) showed how relational coordination might work in the case of work systems that are explicitly 'relational' in nature (see also Gittell, 2000; Gittell, 2002b), but the present study shows that relational coordination might also mediate the effects of systems which were not developed with inter-functional relations specifically in mind.

Third, by breaking down HPWS into their constituent elements, we can see something of the way in which relational coordination might play its mediating role. We might expect relational coordination to be the means through which specifically opportunity-enhancing HR practices have an effect on performance, and this indeed is confirmed in the present study. At the same time - and here the conclusions are a little more tentative-relational coordination also seems to be play a mediating role in the effects of both ability-enhancing and motivationenhancing HR practices. The implication, perhaps not a surprising one, is that more able and better motivated employees are better placed to take advantage of the opportunity represented by relational coordination, and thereby employ organizational resources in a more effective manner (Gittell et al., 2010).

This study's contributions are not confined to the area of relational coordination: the same results and conclusions can also be looked at in terms of what they imply for our second main area of concern, the longstanding debate on the relationship between HPWS and organizational performance. Again, three important contributions can be identified. The first and most basic of these is that relational coordination can be seen to be a mediating variable between HPWS and organizational performance. The present study thus helps answers Boxall et al.'s (2016, p.104) recent demand that 'we must pay better attention to the "O" variable' in the AMO framework. While there seems little doubt that the abilities and motivation of individual employees are important channels through which HR practices are of effect on performance, we need also to look more closely at the opportunities employees have to give effect to their enhanced efforts. One way of looking at this might be to say that as well as employee ability being the counterpart of ability-enhancing practices, and employee motivation being the counterpart of motivation-enhancing practices, we need something like 'opportunity taking' to be the counterpart of opportunity-enhancing practices.

Second, the present study adds to those which suggest that, within the ' $O$ ', more attention might be paid to the antecedents and impact of social relations. We need to take into account 
that such a conclusion arises in part as a result of the research being conducted in a particular kind of setting, where there is a high degree of interdependence in the organization of work. Nonetheless, there seems little reason to follow Jiang et al. (2012) in explicitly separating social relations from the AMO framework. Instead, we might follow those such as Boxall (2013), and see how social relations can be better integrated.

The third contribution to the wider HPWS-performance debate is to provide support to the idea that, in conjunction with social relations, the AMO model might pay more attention to the more structural aspects of the organization of work. In relational coordination, these are present in the interdependences that this form of work coordination builds on and develops. As was seen earlier, Wright and Nishii (2013, p.109) argue that when levels of structural interdependence are high, 'increasing individual performance does not necessarily translate into increased unit performance'. The analysis presented in the present paper would seem to run counter to this. By breaking down HPWS into their constituent parts, we can see how the higher individual performance implied by higher levels of ability and motivation might have an effect on performance via the development of relational coordination. This can only be tentative, but it does suggest that where levels of interdependence are higher, then, on the whole, levels of unit or workplace performance will be higher as well.

We turn finally to the implications of our findings, both for future research and for management practice. For research into relational coordination, we would encourage studies to be undertaken in a broader range of appropriate settings, with attention paid to an understanding of the type of practices conducive to the development of relational coordination - not just in terms of work systems, but also with regard to the attributes and attitudes of individual employees. For research on the HPWS-performance relationship, we would encourage researchers to develop the 'O' side of the AMO model and, as part of this, to incorporate a more refined understanding both of social relations and of the more structural aspects of work organization. The implications of this study for management practice begin with a recognition of the importance of context: relational coordination is not something that will be important in all work system settings. Where relational coordination is likely to be important - where levels of interdependence are high — then we hope that the present study has given a clear indication of the kind of practices that will enhance it and, ultimately, contribute to higher levels of organizational performance. 


\section{References}

Appelbaum, E., Bailey, T., Berg, P. \& Kalleberg, A. (2000). Manufacturing Advantage. Ithaca, NY: ILR Press.

Baron, R. \& Kenny, D. (1986). The moderator-mediator variable distinction in social psychological research. Journal of Personality and Social Psychology, 51, 1173-1182.

Boxall, P. (2013) Building highly-performing work systems. In J. Paauwe, D. Guest and P. Wright (Eds.) HRM and Performance (pp. 47-59). Oxford: Wiley.

Boxall, P. \& Purcell, J. (2016). Strategy and Human Resource Management. London: Palgrave, 4th ed.

Boxall, P., Ang, S. \& Bartram, T. (2011). Analysing the "black box" of HRM. Journal of Management Studies, 48, 1504-1532.

Boxall, P., Guthrie, J. \& Paauwe, J. (2016). Editorial introduction. Human Resource Management Journal, 26, 103-111.

Chowhan, J. (2016). Unpacking the black box. Human Resource Management Journal, $26,112-133$.

Collins, C. \& Clark, K. (2003). Strategic human resource practices, top management team social networks and firm performance. Academy of Management Journal, 46, 740-51.

Collins, C. \& Smith, K. (2006). Knowledge exchange and combination. Academy of Management Journal, 49, 544-560.

Delery, J. \& Doty, D. (1996). Modes of theorizing in strategic human resource management. Academy of Management Journal, 39, 802-835.

Dyer, L. \& Reeves, T. (1995). Human resource strategies and firm performance. International Journal of Human Resource Management, 6, 656-670.

Evans, W. \& Davis, W. (2005). High-performance work systems and organizational performance. Journal of Management, 31, 758-775.

Gant, J., Ichniowski, C. \& Shaw, K. (2002). Social capital and organizational change in high involvement and traditional work organizations. Journal of Economics and Management Strategy, 11, 289-328.

Gerhart, B. (2013). Research on human resources and effectiveness. In J. Paauwe, D. Guest \& P. Wright (Eds.) HRM and Performance (pp. 149-171). Oxford: Wiley.

Gittell, J. (2000). Organizing work to support relational coordination. The International Journal of Human Resource Management, 11, 517-539. 
Gittell, J. (2001). Supervisory span, relational coordination and flight departure performance. Organization Science, 12, 468-483.

Gittell, J. (2002a). Relationships between service providers and their impact on customers. Journal of Service Research, 4, 299-311.

Gittell, J. (2002b). Coordination mechanisms in care provider groups. Management Science, 48, $1408-1426$.

Gittell, J. (2006). Relational coordination. In O. Kyriakidou \& M. Ozbilgin (Eds.), Relational Perspectives in Organizational Studies (pp. 74-94). Cheltenham: Edward Elgar.

Gittell, J. (2008). Relationship and resilience: care provider responses to pressures from managed care. Journal of Applied Behavioral Science, 44, 25-47.

Gittell, J., Fairfield, K., Bierbaum, B., Head, W., Jackson, R., Kelly, M. ... Zuckerman, J. (2000). Impact of relational coordination on quality of care, postoperative pain and functioning, and length of stay. Medical Care, 38, 807-819.

Gittell, J., Seidner, R. \& Wimbush, J. (2010). A relational model of how high performance work systems work. Organization Science, 21, 490-506.

Gittell, J., Weinberg, D., Bennett, A. \& Miller, J. (2008a). Is the doctor in? A relational approach to job design and the coordination of work. Human Resource Management, 47, 729-755.

Gittell, J., Weinberg, D., Pfefferle, S. \& Bishop, C. (2008b). Impact of relational coordination on job satisfaction and quality outcomes. Human Resource Management Journal, $18,154-170$.

Guest, D. (1997). Human resource management and performance. The International Journal of Human Resource Management, 8, 263-276.

Guest, D. (1999). Human resource management-the workers verdict. Human Resource Management Journal, 9, 5-25.

Guest, D. (2011). Human resource management and performance. Human Resource Management Journal, 21, 3-13.

Heavey, A., Beijer, S., Federman, J., Hermans, M., Klein, F., McClean, E. \& Martinson, B (2013). Measurement of human resource practices. In J. Paauwe, D. Guest and P. Wright (Eds.), HRM and Performance (pp. 129-148). Oxford: Wiley.

James, L., Demaree, R. \& Wolf, G. (1984). Estimating within-group interrater reliability with and without response bias. Journal of Applied Psychology, 69, 85-98.

Jiang, K., Lepak, D., Hu, J. \& Baer, J. (2012). How does human resource management influence organizational outcomes?. Academy of Management Journal, 55, 1264-1294. 
Jiang, K., Takeuchi, R. \& Lepak, D. (2013). Where do we go from here?. Journal of Management Studies, 50, 1448-1480.

Khilji, S. \& Wang, X. (2006). "Intended" and “implemented” HRM. The International Journal of Human Resource Management, 17, 1171-1189.

Leana, C. \& van Buren, H. (1999). Organizational social capital and employment practices. Academy of Management Review, 24, 538-555.

LeBreton, J., Burgess, J., Kaiser, R., Atchley, E. \& James, L. (2003). The restriction of variance hypothesis and interrater reliability and agreement. Organizational Research Methods, 6, 80-128.

LeBreton, M. \& Senter, L. (2008) Answers to 20 questions about interrater reliability and interrater agreement. Organizational Research Methods, 11, 815-835.

Lepak, D., Liao, H., Chung, Y. and Harden, E. (2006). A conceptual review of human resource management systems in strategic human resource management research. Research in Personnel and Human Resource Management, 25, 217-271.

Liao, H., Toya, K., Lepak, D. \& Hong, Y. (2009). Do they see eye to eye?. Journal of Applied Psychology, 94, 371-391.

Macky, K. \& Boxall, P. (2007). The relationship between high performance work practices and employee attitudes: an investigation of additive and interaction effects. International Journal of Human Resource Management, 18, 537-567.

Noel, P., Lanham, H., Palmer, R., Leykhum, L. \& Parchman, M. (2013). The importance of relational coordination and reciprocal learning for chronic illness care in primary care teams. Health Care Management Review, 38, 20-28.

Obeidat, S., Mitchell, R. \& Bray, M. (2016). The link between high performance practices and organizational performance. Employee Relations, 38, 578-595.

Paauwe, J. (2009). HRM and performance. Journal of Management Studies, 46, 129-142.

Paauwe, J., Wright, P. \& Guest, D. (2013). HRM and performance. In J. Paauwe, D. Guest and P. Wright (Eds.) HRM and Performance (pp. 1-13). Oxford: Wiley.

Paradi, J., Yang, Z. \& Zhu, H. (2011). Assessing bank and bank branch performance. In W. Cooper, L. Seiford and J. Zhu (Eds.) Handbook on Data Envelopment Analysis (pp. 315-361). New York: Springer, 2nd ed.

Peccei, R., Van de Voorde, K. \& Van Veldhoven, M. (2013). HRM, well-being and performance. In J. Paauwe, D. Guest and P. Wright (Eds.) HRM and Performance (pp. 15-45). Oxford: Wiley. 
Purcell, J. \& Kinnie, N. (2007). HRM and business performance. In P. Boxall, J. Purcell and P. Wright (Eds.), Oxford Handbook of Human Resource Management (pp. 533-551). Oxford: Oxford UP.

Purcell, J., Kinnie, N., Hutchinson, S., Rayton, B. \& Swart, J. (2003). Understanding the People and Performance Link. London: CIPD.

Snell, S. \& Dean, J. (1992). Integrated manufacturing and human resource management. Academy of Management Journal, 35, 467-504.

Singh, K. (2003). The effect of human resources practices on firm performance in India. Human Resource Development International, 6, 101-116.

State Bank of Pakistan. (2012) Banking Statistics of Pakistan. Karachi: SBP Press.

Sterling, A. \& Boxall, P. (2012). Lean production, employee learning and workplace outcomes. Human Resource Management Journal, 23, 227-240.

Thompson, J. (1967). Organizations in Action. New York: McGraw-Hill.

Wall, T. \& Wood, S. (2005). The romance of human resource management and business performance, and the case for big science. Human Relations, 58, 429-462.

Way, S. (2002). High performance work systems and intermediate indicators of firm performance within the US small business sector. Journal of Management, 28, 765-785.

Wright, P. \& Nishii, L. (2013). Strategic HRM and organizational behaviour. In J. Paauwe, D. Guest \& P. Wright (Eds.), HRM and Performance (pp. 97-110). Oxford: Wiley.

Wright, P., Gardner, T., Moynihan, L. \& Allen, M. (2005). The relationship between HR practices and firm performance. Personnel Psychology, 58, 409-446.

Zacharatos, A., Barling, J. \& Iverson, R. (2005). High-performance work systems and occupational safety. Journal of Applied Psychology, 90, 77-93. 


\section{Table 1}

Sampling of the Bank Branches

\begin{tabular}{lcccc}
\hline Areas & $\begin{array}{c}\text { Central } \\
\text { Punjab }\end{array}$ & Federal Areas & KPK & Total \\
\hline Number of Branches in Region & 355 & 185 & 215 & 755 \\
Surveyed Branches & 160 & 83 & 97 & 340 \\
Received HPWS and RC Branches & 61 & 71 & 86 & 218 \\
\% of Surveyed Branches in Region & 38 & 85 & 89 & - \\
HPWS and Performance Matched & 35 & 46 & 39 & 120 \\
Branches & & & & \\
\hline
\end{tabular}

Table 2

\section{Intra Class Correlations for HPWS and Relational Coordination}

\begin{tabular}{lcccc}
\hline Variables & Items & Alpha & ICC1 & ICC2 \\
\hline Skill-enhancing & 4 & 0.738 & 0.414 & 0.738 \\
Motivation-enhancing & 13 & 0.811 & 0.248 & 0.811 \\
Opportunity-enhancing & 12 & 0.824 & 0.281 & 0.824 \\
Overall HPWS & 29 & 0.893 & 0.223 & 0.893 \\
Relational Coordination & 21 & 0.911 & 0.327 & 0.911 \\
\hline Functions & \multicolumn{2}{c}{ HPWS } & Relational Coordination \\
\hline Manager & 0.265 & 0.904 & 0.464 & 0.859 \\
Operations & 0.260 & 0.901 & 0.451 & 0.852 \\
Credit & 0.238 & 0.890 & 0.427 & 0.839 \\
Cash & 0.185 & 0.855 & 0.408 & 0.828 \\
\hline
\end{tabular}


Table 3

Interrater Agreement for HPWS and Relational Coordination (IRA)

\begin{tabular}{lcl}
\hline Functions & $\begin{array}{l}\text { rwgj HPWS } \\
\text { Uniform distribution }\end{array}$ & $\begin{array}{l}\text { Rwgj RC } \\
\text { Uniform distribution }\end{array}$ \\
\hline Manager & 0.93 & 0.91 \\
Operations & 0.91 & 0.88 \\
Credit & 0.92 & 0.87 \\
Cash & 0.89 & 0.87 \\
\hline
\end{tabular}

Table 4

Means, Standard Deviations and Correlations

\begin{tabular}{lccccccc}
\hline Variables & $\mathbf{1}$ & $\mathbf{2}$ & $\mathbf{3}$ & $\mathbf{4}$ & $\mathbf{5}$ & $\mathbf{6}$ & $\mathbf{7}$ \\
\hline 1. HPWS & 1 & -- & -- & -- & -- & -- & -- \\
2. Opportunity-enhancing & $.436^{* *}$ & 1 & -- & -- & -- & -- & -- \\
3. Skills-enhancing & $.321^{* *}$ & $.330^{* *}$ & 1 & -- & -- & -- & -- \\
4. Motivation-enhancing & $.445^{* *}$ & $.496^{* *}$ & $.393^{* *}$ & 1 & -- & -- & -- \\
5. Rel. Coordination & $.419^{* *}$ & $.185^{* *}$ & $.154^{* *}$ & $.177^{* *}$ & 1 & -- & -- \\
6. Deposits to Employee & $.167^{* *}$ & $.141^{* *}$ & $.056^{*}$ & $.015^{*}$ & $.130^{* *}$ & 1 & -- \\
7. Advances to Deposits & $.141^{* *}$ & $.057^{*}$ & $.043^{*}$ & $.092^{* *}$ & $.142^{* *}$ & $.074^{*}$ & 1 \\
\hline Mean & 3.53 & 4.01 & 4.20 & 3.86 & 3.57 & 66.36 & 24.11 \\
SD & 0.298 & 0.693 & 0.748 & 0.643 & 0.318 & 131.85 & 36.27 \\
\hline Correlation significant at 0.01 level, * Correlation significant at 0.05 level &
\end{tabular}


Table 5

Mediation of Relational Coordination (RC)

between HPWS and Performance Outcomes

\begin{tabular}{lccccc}
\hline \multicolumn{1}{c}{ Variables } & RC & \multicolumn{2}{c}{ Deposits/Employee } & \multicolumn{2}{c}{ Advances/Deposits } \\
\hline Age & $(\mathrm{XM})$ & $(\mathrm{XY})$ & $(\mathrm{XMY})$ & $(\mathrm{XY})$ & $(\mathrm{XMY})$ \\
Qualification & -.027 & 17.963 & 18.804 & .589 & .938 \\
Experience & -.026 & 7.067 & 7.867 & -2.849 & -2.678 \\
Gender & .012 & 2.523 & 2.141 & 2.225 & 2.256 \\
Function & $.047^{*}$ & -2.177 & -3.652 & -3.747 & -4.563 \\
Length of service & -.015 & 4.893 & 5.368 & -2.278 & -3.214 \\
HPWS & .031 & 2.215 & 1.253 & 4.484 & 4.852 \\
RC & $.446^{* * *}$ & $74.195^{* * *}$ & $60.268^{* *}$ & $16.380^{* * *}$ & $12.014^{* *}$ \\
R & -- & -- & $31.245^{* * *}$ & -- & $11.846^{* *}$ \\
$\mathrm{R}^{2}$ & 0.429 & 0.182 & 0.194 & 0.170 & 0.193 \\
Adjusted $\mathrm{R}^{2}$ & 0.184 & 0.033 & 0.038 & 0.029 & 0.037 \\
F & 0.177 & 0.025 & .029 & 0.021 & 0.029 \\
Sobel test & $28.24^{* * *}$ & $4.295^{* * *}$ & $4.301^{* * *}$ & $3.745^{* * *}$ & $5.359^{* * *}$ \\
\hline
\end{tabular}

Note: $\mathrm{X}=\mathrm{HPWS}, \mathrm{M}=$ Relational Coordination, $\mathrm{Y}=$ Operational outcomes (Deposits to employee, Advances to deposits), ${ }^{*} \mathrm{p}<.05 ; * * \mathrm{p}<.01 ; * * * \mathrm{p}<.001$. 


\section{Table 6}

\section{Mediation of Relational Coordination (RC)}

between Opportunity-enhancing HR Practices and Performance Outcomes

\begin{tabular}{|c|c|c|c|c|c|}
\hline \multirow[t]{2}{*}{ Variables } & \multirow{2}{*}{$\begin{array}{c}\mathbf{R C} \\
(\mathrm{XM})\end{array}$} & \multicolumn{2}{|c|}{ Deposits/Employee } & \multicolumn{2}{|c|}{ Advances/Deposits } \\
\hline & & $(\mathrm{XY})$ & (XMY) & $(\mathrm{XY})$ & (XMY) \\
\hline Age & -.040 & 17.815 & 19.645 & .069 & .681 \\
\hline Qualification & -.047 & 3.902 & 6.033 & -3.587 & -2.874 \\
\hline Experience & .036 & 5.856 & 4.209 & 3.140 & 2.589 \\
\hline Gender & .038 & -2.725 & -4.449 & -4.057 & -4.634 \\
\hline Function & -.015 & 2.630 & 3.302 & -2.264 & -2.040 \\
\hline Length of service & .035 & 1.815 & .224 & 4.686 & 4.154 \\
\hline $\begin{array}{l}\text { Opportunity-enhancing } \\
\text { HR practices }\end{array}$ & $.085^{* * *}$ & $27.254^{* * *}$ & $23.365^{* * *}$ & $2.918^{*}$ & $1.617^{*}$ \\
\hline $\mathrm{RC}$ & -- & -- & $45.739^{* * *}$ & -- & $15.302^{* * *}$ \\
\hline $\mathrm{R}$ & 0.212 & 0.159 & 0.192 & 0.119 & 0.177 \\
\hline $\mathrm{R}^{2}$ & 0.045 & 0.025 & 0.037 & 0.014 & 0.031 \\
\hline Adjusted $\mathrm{R}^{2}$ & 0.037 & 0.018 & 0.028 & 0.006 & 0.023 \\
\hline $\mathrm{F}$ & $5.88^{* * *}$ & $3.266^{* * *}$ & $4.211^{* * *}$ & $1.799^{*}$ & $3.545^{* * *}$ \\
\hline Sobel test & -- & -- & $3.65^{* * *}$ & -- & $2.78^{* * *}$ \\
\hline
\end{tabular}




\section{Table 7}

\section{Mediation of Relational Coordination (RC) between Skills-enhancing HR practices and Performance Outcomes}

\begin{tabular}{|c|c|c|c|c|c|}
\hline \multirow[t]{2}{*}{ Variables } & \multirow{2}{*}{$\begin{array}{c}\mathbf{R C} \\
(\mathrm{XM})\end{array}$} & \multicolumn{2}{|c|}{ Deposits /Employee } & \multicolumn{2}{|c|}{ Advances/Deposits } \\
\hline & & $(\mathrm{XY})$ & (XMY) & $(\mathrm{XY})$ & (XMY) \\
\hline Age & -.052 & 13.738 & 16.487 & -.347 & .467 \\
\hline Qualification & -.045 & 3.789 & 6.150 & -3.587 & -2.887 \\
\hline Experience & .034 & 6.330 & 4.521 & 3.085 & 2.549 \\
\hline Gender & .032 & -4.668 & -6.379 & -4.303 & -4.809 \\
\hline Function & -.003 & 6.974 & 7.144 & -1.806 & -1.755 \\
\hline Length of service & .038 & 3.545 & 1.522 & 4.789 & 4.190 \\
\hline $\begin{array}{l}\text { Skills-enhancing HR } \\
\text { practices }\end{array}$ & $.064^{* * *}$ & $9.272^{*}$ & $5.892^{*}$ & $1.828^{*}$ & $0.827^{*}$ \\
\hline $\mathrm{RC}$ & -- & -- & $52.726^{* * *}$ & -- & $15.617^{* * *}$ \\
\hline $\mathrm{R}$ & 0.184 & 0.090 & 0.154 & 0.112 & 0.175 \\
\hline $\mathrm{R}^{2}$ & 0.034 & 0.008 & 0.024 & 0.012 & 0.031 \\
\hline Adjusted $\mathrm{R}^{2}$ & 0.026 & 0.001 & 0.15 & 0.005 & 0.022 \\
\hline $\mathrm{F}$ & $4.329^{* * *}$ & $1.016^{*}$ & $2.659^{* *}$ & $1.58^{*}$ & $3.463^{* * *}$ \\
\hline Sobel test & -- & -- & $1.785^{*}$ & -- & $2.635^{* *}$ \\
\hline
\end{tabular}




\section{Table 8}

\section{Mediation of Relational Coordination}

between Motivation-enhancing HR practices and Performance Outcomes

\begin{tabular}{|c|c|c|c|c|c|}
\hline \multirow[t]{2}{*}{ Variables } & \multirow{2}{*}{$\begin{array}{c}\text { RC } \\
(\mathrm{XM})\end{array}$} & \multicolumn{2}{|c|}{ Deposits/Employee } & \multicolumn{2}{|c|}{ Advances/Deposits } \\
\hline & & $(\mathrm{XY})$ & (XMY) & $(\mathrm{XY})$ & (XMY) \\
\hline Age & -.040 & 13.848 & 16.075 & 1.277 & 1.847 \\
\hline Qualification & -.053 & 3.121 & 6.070 & -3.799 & -3.044 \\
\hline Experience & .037 & 7.465 & 5.418 & 1.990 & 1.466 \\
\hline Gender & .047 & -4.473 & -7.108 & -3.371 & -4.045 \\
\hline Function & -.012 & 7.236 & 7.890 & -2.329 & -2.162 \\
\hline Length of service & .038 & 3.828 & 1.691 & 5.016 & 4.469 \\
\hline $\begin{array}{l}\text { Motivation-enhancing } \\
\text { HR practices }\end{array}$ & $.088^{* * *}$ & $3.212^{* *}$ & $1.782^{* *}$ & $5.114^{* * *}$ & $3.865^{* *}$ \\
\hline $\mathrm{RC}$ & -- & -- & $55.701^{* * *}$ & -- & $14.255^{* * *}$ \\
\hline $\mathrm{R}$ & 0.325 & 0.259 & 0.168 & 0.139 & 0.185 \\
\hline $\mathrm{R}^{2}$ & 0.231 & 0.216 & 0.085 & 0.019 & 0.034 \\
\hline Adjusted $\mathrm{R}^{2}$ & 0.129 & 0.131 & 0.057 & 0.011 & 0.025 \\
\hline $\mathrm{F}$ & $6.802^{* * *}$ & $2.693^{*}$ & $4.71^{* *}$ & $2.44^{* * *}$ & $3.868^{* * *}$ \\
\hline Sobel test & -- & -- & $1.98^{* *}$ & -- & $2.356^{* *}$ \\
\hline
\end{tabular}




\section{Appendix A}

\section{HPWS measures}

Employment Security (Delery and Doty, 1996)

- My job is secure as long as I perform well.

- Management tries to avoid dismissing employees.

- I have job in the bank for as long as I want it.

- Management would make a genuine effort to keep my job even under adverse financial conditions.

Training (Delery and Doty, 1996)

- Bank provides me appropriate level job training.

- Employees in my job will normally go through training programs every few years.

- New employees are provided formal training programs to learn job related skills.

- Training programs have provided me opportunities to grow in the bank.

Employee Participation (Delery and Doty, 1996)

- Management involves me in decisions related to overall branch functions.

- Branch management encourage me to participate in decisions about my department.

- My manager asks me for suggestions on how to improve our branch functions.

- Branch management keep open communication with me in this department.

Job Description (Delery and Doty, 1996)

- The duties of my job are clearly defined.

- My job has an up to date job description.

- I have a job description that accurately describes the duties I perform.

- I decide job duties by myself rather than following a formal job description.

Information Sharing (Zacharatos et al. 2005)

- I have enough information to perform my job well.

- Information about branch performance is shared with me.

- It is easy for me to communicate my thoughts to other colleagues in the branch. .

- I am given enough information to understand my role in this department.

Contingent Compensation (Zacharatos et al. 2005)

- My salary package is mainly based on seniority.

- Part of my compensation is based on bank's financial performance.

- My pay is higher than what competitors offer.

- I receive bonuses for the high performance of my department.

Performance Appraisal (Singh, 2003; Delery and Doty, 1996; Snell and Dean 1992).

- My performance appraisal is based on objective quantifiable results.

- I have clear understanding of the objectives and standards of performance appraisal system.

- My Performance appraisal is focused on growth and personal development.

- Branch management provides me feedback on the quality of my performance.

- Decisions such as promotions, pay increase and training are linked with my performance appraisal. 


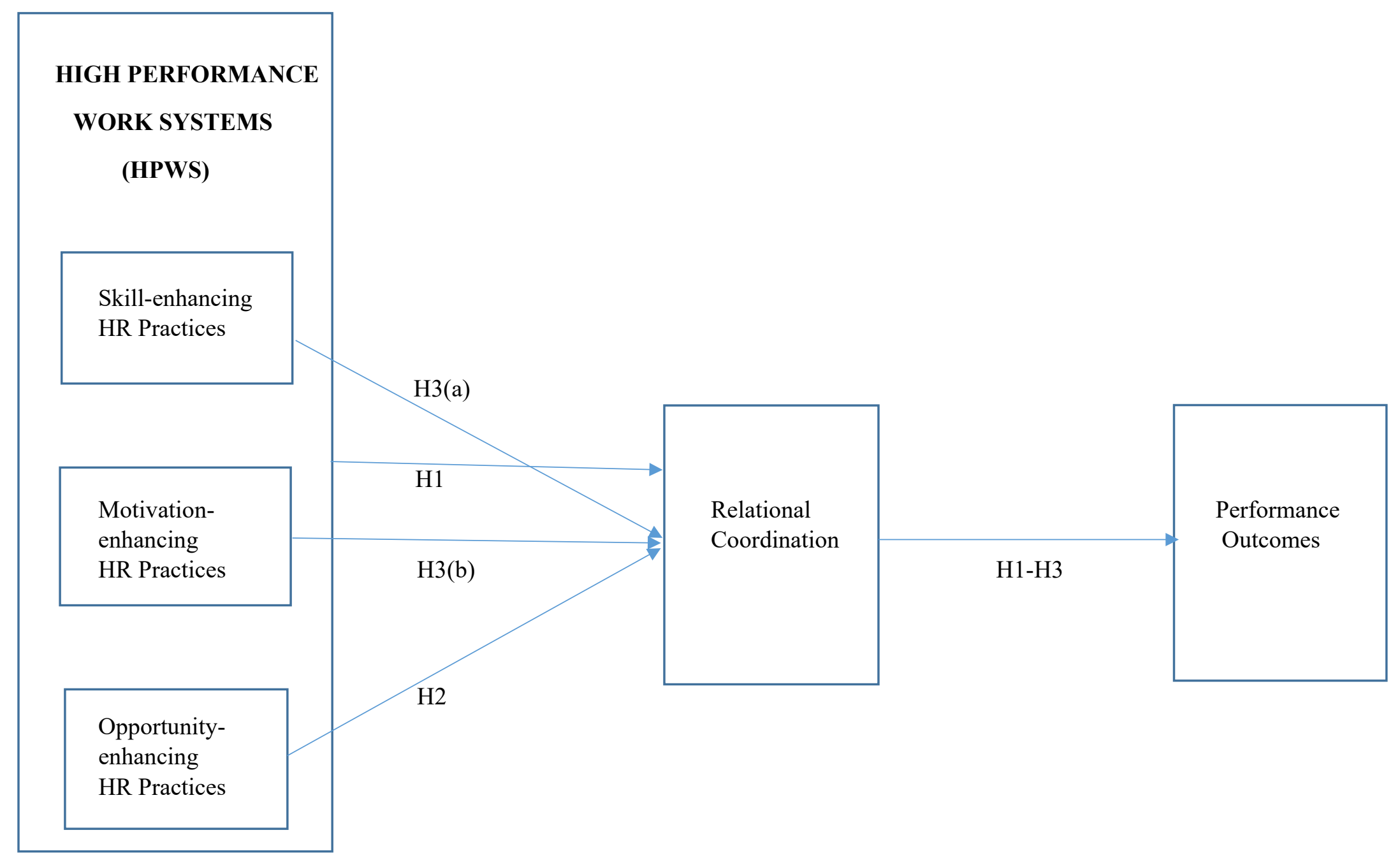

FIGURE 1 Relational Coordination as Mediator between HPWS and Performance Outcomes 